\title{
MOTIVACIÓN DE LOS HECHOS: REFLEXIONES SOBRE LAS DILIGENCIAS PARA MEJOR PROVEER
}

\author{
Roberto Lara Chagoyán* \\ Para Carlos Mario Téllez Guzmán ${ }^{* *}$
}

\begin{abstract}
Sumario:
I. Introducción. II. Algunos antecedentes históricos de las diligencias para mejor proveer. III. Notas características de las diligencias para mejor proveer.IV. Problemas de teoría general del proceso. VI. A manera de conclusión: dos enfoques, una realidad. Bibliografía
\end{abstract}

Resumen: La motivación de los hechos se ha convertido en los últimos años en un tema de gran relevancia, especialmente porque empieza a ser analizado no tanto desde las herramientas tradicionales del Derecho Procesal sino desde la epistemología aplicada al trabajo de los jueces. En este trabajo, se presenta una serie de reflexiones a propósito de un medio de prueba cuyo uso por los tribunales constitucionales puede redundar en la construcción de la premisa fáctica a partir de criterios materiales: las diligencias para mejor proveer. Cumplen el mismo propósito que los amicus curiae del Derecho anglosajón. Se presenta un doble análisis de este tipo de diligencias: uno relacionado con los principios generales de la teoría general del proceso, y otro con los problemas epistemológicos. Lo que se busca con este estudio es llamar la atención sobre la relevancia que pueden tener estas medidas cuando generan una genuina convicción de los jueces. Se considera que, aun cuando el propio sistema normativo ofrece esta gran herramienta epistemológica a los jueces, la misma es poco utilizada en nuestro país. El anhelado cambio cultural y de mentalidad de los jueces en cuanto al compromiso argumentativo no está peleado con la legalidad; por ello, en el artículo se apuesta por maximizar el uso de este tipo de diligencias para tratar de alcanzar el ideal regulativo según el cual la idea de un proceso justo pasa necesariamente por un mínimo cumplimiento de determinados criterios de racionalidad epistemológica.

Palabras clave: principios procesales: dispositivo e inquisitivo. Motivación de los hechos. Pruebas de los hechos. Construcción de la premisa fáctica. Epistemología judicial.

Abstract: Motivation of the facts supporting a legal claim has become in recent years a subject of great consequence, especially since there is a growing tendency to shift the analysis of this subject from the traditional tools provided by General Procedural Law to those offered by an epistemological approach to the manner in which judges work. This paper presents a series of thoughts revolving around a type of evidence the use of which can transcend in the construction

* Suprema Corte de Justicia de la Nación. Doctor en Derecho por la Universidad de Alicante y Licenciado en Derecho por la Facultad de Derecho de la Universidad de Guanajuato.

** Insigne profesor de la Facultad de Derecho de la Universidad de Guanajuato, en donde imparte, entre otras, la materia de Teoría General del Proceso. Este trabajo constituye un sencillo pero sincero homenaje en su honor, por las enseñanzas que ha brindado a tantas generaciones de abogados. 
of a statement of fact through the importation of material criteria, when used by constitutional courts: evidence obtained by a judge sua sponte, this is to say, without a prior motion or request from the parties. This sort of evidence serves the same purpose which amicus curiae serve in Common Law.

This paper presents a double approach to the study of this sort of evidence: the first one related to the mail principles of General Procedural Law, and the second one to certain epistemological problems. The intention of this study is to draw attention about the relevance that the use of this type of evidence may have in generating a genuine conviction in judges. The author considers that even though the Mexican legal system offers this important epistemological tool to judges, it is seldom used by the judiciary. The long sought-after change in judicial culture and mentality regarding an argumentative commitment does not quarrel with the idea of legality. Therefore, this paper calls for a maximization in the use of this type of evidence in order to try to reach the regulation ideal according to which the idea of a just judicial process necessarily entails a minimal compliance with certain criteria of epistemological rationality.

Keywords:Procedural principies. Mechanism and inquisitive. Facts Motivation. Facts Evidence. Construction of factual epistemology.

\section{INTRODUCCIÓN}

No es un secreto para nadie que las diligencias (medidas o providencias) para mejor proveer suponen una ruptura del famoso "principio dispositivo", según el cual el juez sólo debe resolver a partir de lo alegado y probado por las partes. ${ }^{1}$ En lo que sigue, pretendo analizar hasta qué punto es posible admitir que se da esa ruptura, especialmente cuando, ante determinados problemas, los jueces se ven en la disyuntiva traer o no al proceso determinado material probatorio que se considera necesario para resolver un problema de prueba o de calificación. ${ }^{2} \mathrm{El}$ asunto no es de menor importancia porque refleja, al menos, dos posibles actitudes del juez: una más bien conservadora en la que el funcionario se ve a sí mismo como un operador del sistema sin mayor interés que el de cumplir con su encomienda a partir de los mínimos exigibles; y otra según la cual la misión del juez va más allá: el cumplimiento de sus deberes no se agota con el mínimo legal posible sino que amerita un esfuerzo interpretativo que tenga como derrotero la máxima convicción posible sobre la verdad de los hechos, asumida como un deber de justicia. A mi juicio, este análisis no podría llevarse a

\footnotetext{
${ }^{1}$ Es posible encontrar diversas formulaciones latinas de este princicipio, tales como: 1) «Iudex debet judicare secundum allegata et approbata, non autem secundum conscientiam»: 2) «Judex secundum allegata et probata judicare debet non secundum conscientiam»; 3) «Judex secundum allegata et probata partium iudicare debet, non secundum propiam conscientiam»; o simplemente 4) «secundum allegata et probata partium». Al respecto, véase, Picó i Junoy (2007).

${ }^{2}$ Me refiero a la conocida distinción que hace Neil Mac-Cormick entre los problemas de prueba y calificación referidos a la premisa fáctica, en oposición a los de relevancia y de interpretación, atinentes a la premisa normativa (Mac-Cormick, 1978, capítulo IV).
} 
cabo adecuadamente si no lo emprendemos desde una perspectiva teóricafilosófica, ya que lo "problemático" de estas cuestiones se relaciona precisamente con temas tales como la posibilidad del conocimiento o el estatuto filosófico de la verdad.

Las diligencias para mejor proveer constituyen una posibilidad legal, aunque discrecional, para que los jueces decidan o terminen por decidir si un hecho está o no probado. El tema sobre los hechos probados es demasiado extenso, por lo que lo voy a tratar exclusivamente a través de esta figura procesal. Con este acotamiento pretendo mantener la discusión dentro del los márgenes de actuación previstos en el sistema jurídico, intentando resaltar sobre todo los riesgos del uso discrecional. Anticipo que mi posición personal va orientada a ver estas diligencias como genuinos deberes de motivación, por lo que discrepo de quienes ponen el acento en el aspecto discrecional como algo divorciado de los deberes.

Así pues, los problemas que trataré están divididos en dos grupos: unos relacionados con la teoría general del proceso y otros con la motivación de los hechos. Antes haré una breve recensión histórica acerca del origen de estas medidas procesales y esbozaré algunas notas características del concepto.

\section{ALGUNOS ANTECEDENTES HISTÓRICOS DE LAS DILIGENCIAS PARA MEJOR PROVEER}

El antecedente más remoto, de acuerdo con la doctrina mayoritaria, se ubica en las Partidas de Alfonso X, El Sabio, redactadas entre 1254 y 1265, en Castilla. Esencialmente, de las diligencias para mejor proveer se dice lo siguiente: a) se enmarcan en la obligación legal de resolver a cargo del Juez; b) se basan en la aspiración concreta de buscar la verdad; c) es necesaria la existencia de facultades para ejercerlas y d) buscan, concretamente, evitar la precipitación en el dictado de la resolución, a fin de no hacerla nula. De manera concreta, el contenido de algunas de ellas es (Martín Ostos, 1981, p. 38-45): 1) Ley 11, título 22: se autoriza al juez, que dude y no se atreva a resolver, a preguntar a los sabios del lugar, para que le asesoren y, si no es suficiente, al rey para que él resuelva o indique cómo hacerlo; 2) Ley 13, título 14: el juez debe proveer el reconocimiento siempre que lo crea necesario para mayor ilustración; 3) Ley 2, título 12: el juez puede usar la pregunta dirigida a cualquier persona para saber mejor la verdad de los hechos dudosos; y 4) Ley 3, título 22: el juez no debe exponer su sentencia a la "nota de precipitada y nula".

Es hasta el siglo XIX cuando en diversos ordenamientos peninsulares se retoma la institución esencialmente con las mismas características. Entre 
ellas, podemos citar al Reglamento Provisional para la Administración de Justicia de 1835; las leyes que regulan los Consejos Provinciales y el Consejo Real de 1845 - en donde aparece por vez primera la expresión "para mejor proveer" ${ }^{\prime-}$; y las leyes de enjuiciamiento civil de 1855 y de 1881 (esta última sigue rigiendo hasta el momento). Conviene aclarar que es en la ley de 1881 donde se define que estas medidas son, más que autos, "providencias". A decir de Martín Ostos (1981, p. 55), la providencia, a diferencia del auto, no necesita justificación alguna, ya que se trata de una mera facultad del juez que, además, no es recurrible.

Diferentes países hispanoamericanos adoptaron la Ley de Enjuiciamiento Civil de 1855, aun cuando algunos, como México, ya habían alcanzado su independencia. De este modo, el Código de Procedimientos Civiles de 1884 establecía: "Artículo 400. Nunca concluye el término para que el juez, quien aún después de la citación para sentencia o de la vista, puede recibir todas las pruebas que crea necesarias para la aclaración de los hechos y sean las comprendidas en el artículo 129". "Artículo 129. Los jueces y tribunales podrán, para mejor proveer: $1^{\circ}$. Declarar que se traiga a la vista cualquier documento que crean conveniente para esclarecer el derecho de las partes, si no hubiere inconveniente legal; $2^{\circ}$. Decretar la práctica de cualquier reconocimiento o avalúo que reputen necesarios; $3^{\circ}$. Traer a la vista cualesquiera autos que tengan relación con el pleito si su estado lo permite. Al decretar y practicar las diligencias a que este artículo se refiere, los jueces y tribunales se ajustarán a las formalidades prescritas para las pruebas en el tít. V de este libro".

Más adelante, el Código de Procedimientos Civiles para el Distrito Federal y Territorios de $1^{\circ}$ de septiembre de 1932, reguló las medidas para mejor proveer de la siguiente manera: "Artículo 278. Para conocer la verdad sobre los puntos controvertidos puede el juzgador valerse de cualquier persona, sea parte o tercero, y de cualquiera cosa o documento, ya sea que pertenezca a las partes o a un tercero; sin más limitación que la de que las pruebas no estén prohibidas por la ley, ni sean contrarias a la moral". En la actualidad, la institución mantiene esencialmente los mismos elementos e, incluso, se han ampliado las facultades del juez, como se verá más adelante.

\section{NOTAS CARACTERÍSTICAS DE LAS DILIGENCIAS PARA MEJOR PROVEER}

En lo que sigue, responderé a peguntas tales como ¿Qué son? ¿Para qué sirven? ¿Cuál es su objeto? ¿En qué momento procesal pueden ser ordenadas? ¿Qué reglas deben utilizarse para aplicarlas? y ¿En qué casos se pueden ordenar? No pretendo presentar un análisis conceptual rígido ni 
estricto, porque no es el propósito de este trabajo. Más bien pretendo iniciar con un punto de partida básico que nos permita más adelante problematizar a propósito de la práctica de las diligencias para mejor proveer de cara a los principios procesales que las rigen y su condición epistemológica. Por ello, acudiré esencialmente a los contenidos normativos de la legislación mexicana y a la interpretación que de la misma ha realizado la Suprema Corte de Justicia de la Nación, vía jurisprudencia.

1. ¿Qué son las diligencias para mejor proveer? Sencillamente, se trata de prácticas probatorias ordenadas oficiosamente por los tribunales y dirigidas a esclarecer la verdad de algún hecho controvertido. Sus características esenciales son las siguientes: i) son actos de instrucción; ii) surgen de la iniciativa del órgano jurisdiccional; iii) con ellas se busca la verdad; y iv) los nuevos hechos deben ser pertinentes, influyentes y necesarios o convenientes. Podemos complementar esta caracterización a partir de algunas notas negativas (Guasp, 1943, pp. 903 y 904): v) no deben utilizarse para igualar la situación de las partes; vi) tampoco para remediar su descuido o impericia; y vii) los hechos que con ellas se obtengan no deben ser constitutivos de la pretensión. A decir de este autor, el principio de igualdad procesal no tiene un valor absoluto, porque el objeto del proceso no es mantener esa igualad, sino poner fin al litigio. Al respecto, considero que el referido autor apuntaba ya a una distinción entre principios sustantivos y principios adjetivos: los últimos, a mi juicio, sirven para hacer posible la implementación de los primeros, que son los que contienen o promueven derechos fundamentales. Un principio adjetivo tiene, si se quiere, un carácter predominantemente operativo y está dirigido a los jueces con el fin de que éstos administren de la mejor manera posible la prevalencia de los principios sustantivos. La igualdad procesal es claramente un principio de carácter adjetivo, y Guasp, advirtiendo quizás la ambigüedad del término igualdad, intenta destacar que la finalidad del proceso no es esencialmente mantener la igualdad procesal (adjetiva), sino resolver el caso concreto en donde, eventualmente, podrá dilucidarse sobre una cuestión de igualdad (sustantiva)..

2. Por otro lado, si nos preguntamos ¿para qué sirven?, podemos decir que su fin último es mejorar la administración de justicia. Para ello, se pueden advertir dos fines próximos: uno de tipo objetivo y uno de tipo subjetivo. El primero consiste en mejorar el proceso; así, las medidas buscan precisamente una decisión más acorde con la realidad del supuesto planteado; se llevan a cabo para "proveer mejor", para que el resultado sea más acertado. De acuerdo con el segundo de los fines, las medidas se dirigen a lograr la convicción del juez sobre el material probatorio; con ellas, es posible despejar las dudas que pueda tener antes de dictar la sentencia. Desde luego, 
no debe perderse de vista que esta doble función de de las diligencias juega especialmente en los llamados casos difíciles y, más específicamente, a la hora de resolver problemas de prueba asociados a la premisa fáctica del silogismo con el que se resuelve un caso difícil.

Como se verá más adelante, ni el concepto ni la finalidad de las diligencias para mejor proveer están exentos de problemas, ya que muchas veces, paradójicamente, el empleo de estas medidas viene a alterar algunos principios que se consideran fundamentales en el proceso, como es el caso del principio dispositivo. Por lo demás, ambas cuestiones (objetiva y subjetiva) tienen como factor común la búsqueda de la verdad, lo cual hace de inmediato saltar de su silla a muchos juristas prácticos que ven en ello amenazada la pureza del Derecho. Más adelante volveré con este problema.

3. En otro orden de ideas, es importante precisar que el objeto de las diligencias para mejor proveer puede ser cualquier tipo de medio de prueba; baste, como ejemplo, remitirnos al contenido del Código Federal de Procedimientos Civiles que, en su artículo 79, señala: “[p]ara conocer la verdad, puede el juzgador valerse de cualquier persona, sea parte o tercero, $y$ de cualquier cosa o documento, ya sea que pertenezca a las partes o a un tercero, sin más limitaciones que las de que las pruebas estén reconocidas por la ley y tengan relación inmediata con los hechos controvertidos (...)".

4. Otra pregunta interesante con respecto a las notas características de las diligencias para mejor proveer es: ¿en qué momento procesal pueden ser ordenadas? Tradicionalmente, se ha sostenido que puede ser en cualquier momento del proceso. Así, por ejemplo, el segundo párrafo del artículo 79 de nuestro Código Federal de Procedimientos Civiles, los tribunales no tienen límites temporales para ordenarlas. Ligada a esta pregunta, podemos formularnos esta otra: ¿qué reglas deben utilizarse para aplicarlas? Comúnmente, se acepta que la regulación de estas medidas no es la misma que para cualquier otra prueba. En nuestro país, por ejemplo, el referido artículo 79 prescribe que para los tribunales no rigen las limitaciones y prohibiciones, en materia de prueba, establecidas en relación con las partes. Así las cosas, si las diligencias para mejor proveer pueden ordenarse en cualquier tiempo y si su práctica no tiene las mismas limitaciones normativas que tienen otras pruebas, entonces es posible afirmar que la formalidad del procedimiento queda subordinada al interés epistemológico de encontrar la verdad en el proceso.

Es importante señalar que en la actual legislación mexicana se ha elimi-

\footnotetext{
${ }^{3}$ El texto decía: “...sin más limitación que la de que las pruebas no estén prohibidas por la ley, ni sean contrarias a la moral".
} 
nado la limitación de "ser contrarias a la moral" que mantenía el Código de Procedimientos Civiles del Distrito Federal y Territorios, de $1932 .{ }^{3}$ Así, tenemos un problema menos: discriminar medios de convicción contrarios a la moral de los que no lo son, es una tarea de tintes metafísicos que cualquier (o casi cualquier) juzgador desearía evitar.

5. Si nos preguntamos, por otra parte, en qué casos se pueden ordenar las diligencias para mejor proveer, la respuesta viene dada por la necesidad epistemológica del juez, es decir, en cualquier tipo de caso en el que exista una duda razonable que debiera despejarse. En nuestra legislación, el artículo 80 del Código Federal de Procedimientos Civiles dispone:

\begin{abstract}
“Artículo 80. Los tribunales podrán decretar, en todo tiempo, sea cual fuere la naturaleza del negocio, la práctica, repetición o ampliación de cualquier diligencia probatoria, siempre que se estime necesaria y sea conducente para el conocimiento de la verdad sobre los puntos controvertidos. En la práctica de esas diligencias, obrarán como lo estimen procedente, para obtener el mejor resultado de ellas, sin lesionar los derechos de las partes, y procurando en todo su igualdad".
\end{abstract}

Las anteriores notas, extraídas de la legislación vigente, no se alejan demasiado de las que ofrece la teoría más representativa. En suma, podemos estipular que las diligencias para mejor proveer son actos de instrucción que surgen de la iniciativa del órgano jurisdiccional dirigidas a la búsqueda de la verdad de los hechos en el proceso; su objeto puede ser cualquier cosa o documento, ya sea que pertenezca a las partes o a un tercero; su práctica no está regida por las limitaciones y prohibiciones en materia de prueba establecidas en relación con las partes y puede tratarse de cualquier diligencia probatoria, siempre que se estime necesaria y sea conducente para el conocimiento de la verdad sobre los puntos controvertidos.

6. Por su parte, la Suprema Corte de Justicia de la Nación tampoco se ha alejado de estas notas definitorias de las diligencias para mejor proveer a la hora de la creación jurisprudencial, según puede advertirse en varios criterios. Por ejemplo, en materia civil, en una tesis aislada de 1984, la Corte sostuvo que el artículo 79 del Código Federal de Procedimientos Civiles “...da gran amplitud al Juez para realizar cualquier diligencia o admitir pruebas para mejor proveer, sin limitación temporal, con las solas restric-

\footnotetext{
${ }^{4}$ Tesis aislada emitida por la Tercera Sala de la Suprema Corte de Justicia de la Nación, publicada en Semanario Judicial de la Federación, Séptima Época, volumen 187-192 cuarta parte, página 124, rubro: “"DILIGENCIAS PARA MEJOR PROVEER”. Precedente: Amparo directo 238/82. Guadalupe de la Rosa Salazar. 27 de agosto de 1984. Unanimidad de cuatro votos. Ponente: J. Ramón Palacios Vargas. Secretario: Víctor Hugo Díaz Arellano.
} 
ciones de que no se practiquen diligencias o se admitan pruebas que sean contrarias a la ley". ${ }^{4}$ En materia penal, el contenido de los artículos 180 y 384 del Código Federal de Procedimientos Penales, dota al juzgador de similares competencias para ilustrar su criterio, aun encontrándose el proceso para dictar sentencia. ${ }^{5}$ Más recientemente, en el 2004, En materia de amparo administrativo, la Corte ha señalado que en el mismo acuerdo en el que se decrete la suspensión provisional, se requiera a las autoridades responsables la presentación de algún documento que se considere indispensable para mejor proveer. ${ }^{6}$

En materia de controversias constitucionales, en un criterio de 2002, la Corte señaló que el Ministro instructor puede "ordenar, de oficio, en todo tiempo, que se recaben y desahoguen las pruebas necesarias para la mejor resolución del asunto, entendiéndose por la expresión «en todo tiempo», cualquier etapa del procedimiento de las controversias constitucionales". ${ }^{7}$

Finalmente, traigo a colación un criterio del año 1995 en el que la Corte sostuvo que el hecho de que un tercero aporte pruebas a la controversia

\footnotetext{
${ }^{5}$ Tesis aislada emitida por la Sala Auxiliar, publicada en el Semanario Judicial de la Federación Séptima Época, 175-180, Séptima Parte, página 406, rubro. “PRUEBAS PARA MEJOR PROVEER EN JUICIO PENAL. FACULTAD DEL JUEZ PARA DECRETARLAS". Precedente: Amparo directo 1465/ 80. Manuel Hernández Rodríguez. 19 de septiembre de 1983. Mayoría de tres votos. Disidentes: Guillermo Guzmán Orozco y Felipe López Contreras. Ponente: Tarsicio Márquez Padilla.
}

${ }^{6}$ Tesis 2a./J. 27/2004, emitida por la Segunda Sala, publicada en el Semanario Judicial de la Federación y su Gaceta; Novena Época; tomo XIX, marzo de 2004, página 354, rubro: "SUSPENSIÓN PROVISIONAL EN AMPARO ADMINISTRATIVO. EL JUEZ DE DISTRITO PUEDE RECABAR OFICIOSAMENTE PRUEBAS PARA MEJOR PROVEER, PERO NO POSTERGAR SU DECISIÓN". Precedente: Contradicción de tesis 19/2003-PL. Entre las sustentadas por el Séptimo y Décimo Tercer Tribunales Colegiados, ambos en Materia Administrativa del Primer Circuito. 5 de marzo de 2004. Mayoría de tres votos. Disidentes: Margarita Beatriz Luna Ramos y Juan Díaz Romero. Ponente: Guillermo I. Ortiz Mayagoitia. Secretaria: Claudia Mendoza Polanco.

${ }^{7}$ Jurisprudencia P./J. 37/2002, emitida por el Tribunal Pleno, publicada en el Semanario Judicial de la Federación y su Gaceta, Novena Época, tomo XVI, agosto de 2002, página 906, rubro: “PRUEBAS PARA MEJOR PROVEER EN CONTROVERSIAS CONSTITUCIONALES. EL TRIBUNAL PLENO DE LA SUPREMA CORTE DE JUSTICIA DE LA NACIÓN, SI LO CONSIDERA NECESARIO, PODRÁ ORDENAR, DE OFICIO, QUE SE RECABEN Y DESAHOGUEN AUNQUE YA LE HAYA SIDO PRESENTADO EL PROYECTO PARA SU RESOLUCIÓN (INTERPRETACIÓN DEL ARTÍCULO 35 DE LA LEY REGLAMENTARIA DE LAS FRACCIONES I Y II DEL ARTÍCULO 105 DE LA CONSTITUCIÓN POLÍTICA DE LOS ESTADOS UNIDOS MEXICANOS)". Precedente: Recurso de reclamación 128/2002, deducido de la controversia constitucional 39/2001. Municipio de San Miguel Yotao, Estado de Oaxaca. 12 de agosto de 2002. Unanimidad de nueve votos. Ausentes: Genaro David Góngora Pimentel y José Vicente Aguinaco Alemán. Ponente: Juan Díaz Romero. Secretario: Pedro Alberto Nava Malagón.

\footnotetext{
${ }^{8}$ Tesis aislada P. CIX/95, emitida por el Tribunal Pleno, publicada en el Semanario Judicial de la Federación y su Gaceta, Novena Época, tomo II, noviembre de 1995, página 86, rubro: “CONTROVERSIA CONSTITUCIONAL. PARA MEJOR PROVEER, ES LEGAL AGREGAR A LOS AUTOS LAS PRUEBAS OFRECIDAS POR UN TERCERO". Precedente: Recurso de reclamación en la controversia constitucional 11/95. Roberto Madrazo Pintado, gobernador Constitucional del Estado de Tabasco, Pedro Jiménez León, presidente de la Gran Comisión de la LV Legislatura al Congreso del Estado de Tabasco y Andrés Madrigal Sánchez, procurador general de Justicia de dicho Estado. 12 de octubre de 1995. Unanimidad de once votos. Ponente: Olga Sánchez Cordero. Secretaria: Norma Lucía Piña Hernández.
} 
constitucional puede ser entendido como una auténtica diligencia para mejor proveer. ${ }^{8}$ A mi juicio, esta tesis da lugar a que en el marco de las diligencias para mejor proveer, los terceros al juicio puedan aportar pruebas a la manera de amicus curiae. ${ }^{9}$

Como puede verse, la Corte mexicana se ha pronunciado a favor de la práctica de estas diligencias, confirmando prácticamente todas las notas características antes referidas. Así, el interés epistemológico no parece estar puesto en duda por el máximo intérprete de la Constitución.

\section{PROBLEMAS DE TEORÍA GENERAL DEL PROCESO}

La discusión sobre la conveniencia y viabilidad de las diligencias para mejor proveer se inscribe en la elección de alguno de los dos grandes principios procesales ${ }^{10}$ que han estado presentes en la mente de los grandes procesalistas: el dispositivo y el inquisitivo (Martín Ostos, 1981, p. 153 y ss.). El principio dispositivo tiene dos aspectos (Davis Echandía, 1997, p. 60): 1) que corresponde a las partes iniciar el proceso formulando la demanda y en ella sus peticiones y desistir de ella; y 2) que corresponde a las partes solicitar las pruebas sin que el juez pueda ordenarlas de oficio. En otras palabras, de acuerdo con este principio, corresponde a las partes la iniciativa en general en el proceso y el juez debe atenerse exclusivamente a la actividad de éstas sin que le sea permitido tomar decisiones encaminadas a incoar el proceso ni a establecer la verdad para saber cuál de las partes tiene la razón en la afirmación de los hechos.

Por su parte, el principio inquisitivo, por un lado, otorga al juez la función de investigar la verdad por todos los medios legales a su alcance, sin que la inactividad de las partes lo obligue ni lo limite a decidir únicamente sobre los medios que ellas le lleven o le pidan y, por otro lado, faculta al juez para iniciar de oficio el proceso y para dirigirlo con iniciativas personales (D. Echandía, 1997, pp. 60-61). El principio dispositivo constituye la supervivencia del proceso común nacido en Italia en la Edad Media, pero sobre todo un fruto del liberalismo decimonónico (Martín Ostos, 1981, p. 156). Con la revolución francesa y la puesta en práctica del principio «laissez faire», llega a limitarse la actuación del Estado incluso en los procesos jurisdiccionales. De este modo - dice el mismo autor -, el papel del Estado

\footnotetext{
${ }^{9}$ Más adelante haré una referencia con relación al amicus curiae, Por ahora, baste decir que aun cuando existe esta posibilidad legal, la Suprema Corte de Justicia no puso en práctica esta facultad de manera genuina hasta el 2007, cuando resolvió el caso de los militares con VIH; infra, § VI.

${ }^{10}$ Los llamados principios procesales son "directrices que inspiran tanto su desarrollo como el ordenamiento jurídico procesal de ese Estado en ese momento histórico determinado" (M. Ostos, 1981, p. 153.
} 
quedó limitado a la "mera administración de justicia, sin inmiscuirse en la marcha del proceso cuando los intereses en juego sean netamente privados" (Id., p. 157). La limitación de la actuación judicial quedó reflejada en los códigos elaborados a partir de esa época en lo que se conoce como el movimiento codificador. Piero Calamandrei llegó a afirmar que el proceso de tipo dispositivo corresponde a una concepción individualista y liberal del Estado y que el liberalismo confirió un poder exagerado sobre el proceso civil, el cual es considerado, desde entonces, como un asunto particular de las mismas (Calamandrei, 1951, p. 160). En esta línea, Fix-Zamudio sostiene que el principio dispositivo no es sino la expresión, en el campo procesal, del principio de la libertad de estipulaciones o de la "autonomía de la voluntad" que predomina en el Derecho privado (Fix-Zamudio, 1964, pp. 19).

Como suele suceder, esta tendencia tuvo una respuesta a partir de la opuesta: el principio inquisitivo al que ya me he referido. El origen de este principio se remonta al siglo XIII a cargo, por un lado, de la Inquisición y, por otro, de la mayoría de los tribunales penales de los reinos de la Europa continental. ${ }^{11} \mathrm{La}$ "mala fama" del modelo se da a partir de la ilustración, en el siglo XVIII, que fue, como se dijo, cuando surge con fuerza el principio dispositivo. Con todo, es unánime la opinión de los teóricos en el sentido de que ninguno de estos sistemas, principios o modelos se aplica con carácter exclusivo.

Pues bien, sin que reine la paz entre quienes defienden con mayor o menor intensidad alguno de estos principios, si uno se pregunta a cuál de ellos se pueden asociar más adecuadamente las diligencias para mejor proveer, la respuesta sería, sin duda, al principio inquisitivo. Aparece aquí una paradoja: la búsqueda de la verdad en el proceso parece una preocupación saludable desde varios puntos de vista (entre ellos el de la justicia como ideal racional), pero el modelo inquisitivo parece ya superado por su excesiva confianza de encontrarla a toda costa; el modelo dispositivo, por su parte, provoca (o puede provocar) en el juzgador una peligrosa impasividad que le podría orillar a ser indiferente ante la verdad de los hechos, preocupándose más porque se cumplan las reglas y el proceso se conduzca con base en el deseo de las partes. Así, por un lado, tenemos en un extremo el modelo dispositivo lejano a la práctica de las diligencias para mejor proveer $y$, en el otro extremo, un modelo inquisitivo en el que estas diligencias encuadran perfectamente pero que sufre de un desprestigio y un paulatino abandono.

${ }^{11}$ Así lo afirma Francisco Tomás y Valiente, véase:

http://www.vallenajerilla.com/berceo/florilegio/inquisicion/procesopenal.htm. 
Desde mi punto de vista, los problemas que hay que superar para tratar de eliminar esta paradoja quedan planteados mediante las siguientes preguntas: ${ }^{12}$ ¿Existe contradicción entre el principio «da mihi factum, dabo tibi ius» y las diligencias para mejor proveer?; ¿se da una penetración inquisitiva en el principio dispositivo?; con las medidas ise altera el principio «Iudex debet judicare secundum allegata et approbata, non autem secundum conscientiam»?; y finalmente, ¿implican éstas una excepción justificada del modelo inquisitivo?.

1. Los defensores fervientes del principio «da mihi factum, dabo tibi ius» tratan de delimitar (si se quiere, "purificar") las funciones del juez: decir el Derecho. Con este intento de purificación se llega a identificar al juzgador con un ente superior a las partes, parecido a Zeus, que desde las alturas del Olimpo lleva a cabo sus dictados de justicia. ${ }^{13}$ Esta visión coloca a las partes en un estatus inferior al juez, pero curiosamente les otorga un gran poder: el de llevar los hechos al proceso tal y como cada una de ellas las entiende o interpreta. Cerrado el círculo, Zeus debe tomar en cuenta más que nada la habilidad técnica de las partes para acercar datos al proceso y quien aporte los "mejores" tendrá la razón. A mi juicio, importantes problemas que merman la (buena) práctica del Derecho en países como el nuestro tienen su génesis en esta concepción: la creencia en la superioridad (intelectual, política y moral) de los jueces; el carácter meramente instrumental de los jueces de quienes se espera una mera conducción del proceso; ${ }^{14}$ el considerar que los jueces que se aproximan a la filosofía o a la ciencia, se extralimitan en sus funciones; y que la epistemología no es un asunto jurisdiccional.

No nos engañemos: la mayoría de los abogados postulantes son empresarios - y no hay nada de malo en ello - que defienden los intereses de sus clientes y no necesariamente buscan (ni tienen por qué hacerlo) el esclarecimiento de unos hechos determinados. Acaso, buscan que su contrapar-

\footnotetext{
${ }^{12}$ Estos problemas son tratados por Martín Ostos (1981, capítulo cuarto) desde una perspectiva dogmática. Mi intención es dialogar un poco con estos problemas desde una perspectiva más epistemológica, pues considero en general que el (buen) uso de estas medidas está justificado y que nada de malo hay en alejarse de una interpretación ortodoxa de esos principios.
}

${ }^{13}$ Zeus representa el modelo "clásico" del Derecho: el Derecho visto en forma de pirámide o de código; el Derecho aparece como algo que viene "desde arriba" (desde lo alto del Olimpo), que adopta la forma de la ley. Representa las exigencias del Estado liberal de Derecho del XIX (Cfr. Ost, 1993, pp. 170, 172176; Lara, 2006, 439-439).

\footnotetext{
${ }^{14}$ Carlos de Silva Nava comentaba en una ocasión que el abuso y el extremo del principio dispositivo llevaría al absurdo siguiente (al parecer extraído de la realidad): una persona lleva al juzgado su demanda. Pasan los días y él no sabe nada. Acude al juzgado y pregunta por su caso. El juez le dice: "tengo tu demanda, pero nunca me pediste que la admitiera". El abogado, por escrito, hace una promoción en la que formalmente solicita que la demanda sea admitida. El juez notifica al abogado que la demanda fue admitida. Pasa el tiempo y nada sucede. El abogado acude de nueva cuenta ante el juez y pregunta si se ha emplazado al demandado. El juez contesta: "nunca me pediste que emplazara". El relato corre a lo largo del proceso.
} 
te no distorsione los hechos en la medida que ello les perjudique, pues podrían perfectamente admitir algún tipo de distorsión que les resulte beneficiosa. El juez, en cambio, está (o debería estar) más cercano a la búsqueda de la verdad, pero para ello debería adoptar un punto de vista más terrenal y humano; tendría que aceptar que no es omnisciente - que no es un dios-. Así, bien le convendría bajar del Olimpo y adoptar otra condición más terrenal; ${ }^{15}$ sería mejor que valorara la suficiencia o insuficiencia de la información sobre los hechos y, posteriormente, actuara en consecuencia. Para ello, necesita el poder de Zeus, pero también la condición de sabio de Hércules y una virtud más: entender la complejidad del Derecho postmoderno, es decir, un Derecho en el que interviene una multiplicidad de actores jurídicos (el protagonismo no lo tienen ya sólo el juez y el legislador, sino también las asociaciones, los particulares, etc.); un Derecho en el que se actualiza una superposición de funciones (entre la jurisdicción y la administración, las autoridades judiciales y administrativas y los comités de ética, etc.); un Derecho en el que existen numerosas instancias (supraestatales, autonómicas, del mundo de los negocios, etc.); $\mathrm{y}$, finalmente, un Derecho en el que se distingue una variedad de tipos de normas (normas de fin, principios, reglas, etcétera). ${ }^{16}$

Lo anterior implica entonces que la búsqueda de la verdad de los hechos es una tarea propia de los jueces, o al menos de los que se identifican con el modelo de Hermes. Si aceptamos esto, entonces podemos también aceptar que el principio «da mihi factum, dabo tibi ius» ha sido tradicionalmente mal interpretado: se ha pensado erróneamente que, bajo el principio dispositivo, el juez debe atender estrictamente lo que las partes le plantean sin que pueda jamás ir más allá; que los jueces no dudan, sólo resuelven los problemas planteados con los materiales que las partes aportan; y que es exclusivamente papel de las partes allegar al juez los medios de prueba que dan cuenta de los hechos litigiosos. Esa interpretación es demasiado simple, pues supone que el juez no tendrá dudas o que no existen más que casos fáciles.

Desde mi punto de vista, el principio «da mihi factum, dabo tibi ius» no se refiere más que a las pretensiones de las partes y no realmente a los hechos en el proceso. Obviamente, toda pretensión tiene una base fáctica, pero tam-

\footnotetext{
${ }^{15}$ Los realistas asociarían este modelo de juez con la figura del semidiós Hércules que se somete a trabajos agotadores de juzgar. En lugar de una pirámide, representa la imagen de un embudo. Dworkin y Ost sugieren, a su manera, este modelo de juez: el primero se refiere al juez infalible, sabio, capaz de encontrar la célebre "única respuesta correcta"; el segundo, representa las exigencias del Estado social o asistencial del siglo XX (Lara, pp. 438-439).

${ }^{16}$ Hermes es el mensajero de los dioses, el que siempre está en movimiento. Hermes está a la vez en el cielo, en la tierra y en los infiernos; es el mediador universal, el gran comunicador. No conoce otra ley que la circulación de los discursos. A diferencia de la pirámide de Júpiter y del embudo de Hércules, Hermes adopta la forma de una red (Ost, 1993, p. 182-194).
} 
bién un interés determinado que puede eventualmente tergiversar dicha base. El juez va a determinar quién tiene razón conforme a Derecho, pero como la mayoría de las normas jurídicas tienen un supuesto de hecho, el juez debe en primer lugar esclarecer qué fue lo que aconteció en la realidad empírica, pues sólo así podrá determinar qué consecuencia jurídica corresponde a tales hechos. Ciertamente, las partes ofrecerán su versión sobre los hechos y tratarán de probarla, pero será el juez quien resolverá en definitiva y para ello tiene un gran poder. Ahora que si no se quiere caer en un decisionismo, el juez ha de asegurarse de que los hechos sobre los que va a dictar o ("decir") el Derecho realmente ocurrieron, y eso es responsabilidad exclusiva suya, no de las partes. El juez valorará la pretensión -que yo entiendo como un acto de voluntad vinculado a un interés determinado - a la luz de dos tipos de elementos: los estrictamente epistemológicos y los normativos surgidos del sistema jurídico de que se trate. Por ello, no es posible admitir la interpretación de «da mihi factum, dabo tibi ius» como "dame los hechos" (dime qué fue lo que sucedió, según tu interpretación), mientras yo me limitaré a señalar cuál es la consecuencia jurídica correspondiente". Más bien, debería entenderse como «da mihi petitio, dabo tibi ius», es decir, «dame tu pretensión (dime cuál es la interpretación de los hechos sumada a tu interés), mientras yo me encargo de verificar los hechos y determinar, conforme a Derecho, si tu interés debe o no prevalecer".

2. Corresponde ahora analizar si se da una penetración inquisitiva en el principio dispositivo. Desde mi punto de vista, el modelo inquisitivo también ha sido mal entendido, debido a la mala fama que adquirió en la antigüedad gracias a que no se había separado el concepto de delito del concepto de pecado. Se estaba entonces en una era pre-moderna, en la que la confianza en encontrar la verdad era absoluta. Pero bien entendidas las cosas, el modelo inquisitivo tenía, al menos, una virtud: permitía - quizás desmesuradamente en la antigüedad - la existencia de jueces pro-activos. Hoy se abraza el modelo dispositivo con gran avidez y se desprecia, sin más, todo aquello que tenga un tufo inquisitivo. Me parece que al aceptar los modelos de juez Hércules o Hermes, se podría romper esta falsa dicotomía, pues en realidad la (buena) argumentación jurídica y, sobre todo, su adecuada detección, es la mejor herramienta con la que se cuenta para delimitar el enorme poder de los jueces. Si se me quiere forzar a decir que las diligencias para mejor proveer son de naturaleza inquisitiva, yo diría que sí, pero que está plenamente justificado su buen uso. Y esa bondad es posible medirla a través de los criterios de evaluación y de racionalidad práctica como los que mencionan, por ejemplo, MacCormick o Alexy. ${ }^{17}$

\footnotetext{
${ }^{17}$ Manuel Atienza hace un magnífico resumen de estos criterios en su obra Las razones del Derecho. Teorías de la argumentación jurídica (Atienza, 1997).
} 
Así las cosas, considero que no parece adecuado asociar la mala fama del modelo inquisitivo con la buena práctica de las diligencias para mejor proveer, pues la finalidad de éstas no es, en modo alguno, aumentar injustificadamente el poder de los jueces, sino darles su justa dimensión como protagonistas activos del proceso en aquellos casos en los que el material probatorio resulta insuficiente para resolver.

3. ¿Se altera el principio «Iudex debet judicare secundum allegata et approbata, non autem secundum conscientiam»? La formulación de este principio encierra, a mi juicio, una ambigüedad que puede causar no pocos problemas. Por una parte, se puede entender como que el juez no puede ni debe jamás emplear su propia conciencia como juzgador para resolver un caso; pero también puede interpretarse en el sentido de que los jueces, al resolver, deben ser imparciales. Quien entienda la formulación en el primero de los sentidos podría estar llevando al extremo máximo del principio dispositivo, considerando que los jueces son poco más que autómatas del Derecho. En cambio, entenderlo conforme a la segunda interpretación supone no más que una obviedad. Como lo más probable es que se entienda en el primero de los sentidos, entonces conviene tener en cuenta algunas consideraciones.

¿Qué significa resolver [sólo] según la conciencia? La respuesta más constructiva o, parafraseando a Dworkin, la respuesta que ve a esta interrogante bajo su mejor luz, es que el juez debe resolver desde el Derecho y sólo desde el Derecho, esto es, ejerciendo la virtud de la independencia judicial. Esto, por supuesto, no significa que los jueces deban resolver de forma "inconsciente" - como podría sugerir una lectura esencialista del brocardo latino - sino todo lo contrario: los jueces verdaderamente conscientes son los independientes. Obviamente que esta interpretación vale con mayor fuerza para los llamados "casos fáciles" en los que la operación del juez es relativamente sencilla: aplicar una norma clara (exenta de problemas de interpretación y relevancia) a un caso concreto (exento de problemas de prueba y calificación) (Mac-Cormick, 1978, capítulo IV). En otro tipo de casos, la independencia judicial, al menos, se complica a la hora de resolver los problemas que originan la dificultad de los casos. Evidentemente, siguen siendo jurídicas la identificación de la norma aplicable, las interpretaciones que de las normas se hagan, la determinación de los hechos probados y la calificación jurídica de éstos; sin embargo, a la hora de resolver estos problemas se hace presente la necesidad de echar mano en algunos casos de la ciencia, en otros de criterios materiales, etcétera, que podrían llegar suponer que no se está resolviendo "desde el Derecho y sólo desde el Derecho".

Precisamente en este punto es donde puede cuestionarse el papel de 
las diligencias para mejor proveer: el establecimiento de la premisa fáctica del razonamiento judicial a partir de elementos prima facie extra jurídicos por ejemplo científicos - podría dejar en entredicho el principio que se analiza. Considero que el principio no se altera en modo alguno, por varias razones. En primer lugar, porque el hecho de que una norma del sistema faculte a los jueces a practicar las diligencias para mejor proveer hace jurídica su práctica. En otras palabras, las referidas diligencias no constituyen en ningún caso una mera ocurrencia de los jueces, sino que es el sistema jurídico el que prevé una necesidad epistemológica y trata de resolverla reconociendo esa facultad a los jueces. En segundo lugar, porque la administración de los recursos epistémicos obtenidos mediante la práctica de estas diligencias forma parte del razonamiento judicial, lo cual implica que los datos duros están siendo utilizados por el juez para "hacer derecho" en el sentido de los realistas, es decir, para resolver casos concretos. Así, si la resolución del caso precisa de elementos probatorios extraordinarios - por no ser llevados al proceso por las partes -, entonces la sentencia obtenida - que constituirá parte del Derecho creado - habrá sido formulada en parte gracias a estos elementos. $Y$ en tercer lugar, porque la naturaleza de los elementos probatorios obtenidos no es esencialmente distinta a la de los elementos probatorios que las partes llevan al proceso; lo único que cambia es que en éstos últimos está presente la pretensión de las partes, mientras que en las diligencias para mejor proveer no hay "pretensión" del juez sino un interés epistemológico.

4. Corresponde ahora analizar si las diligencias para mejor proveer implican una excepción justificada del modelo inquisitivo. Me parece que la formulación misma del enunciado coloca al defensor de las diligencias para mejor proveer en un estado incómodo, pues sea cual fuere la respuesta daría pauta para pensar que su práctica tiene, al menos, un origen viciado. En efecto, si la respuesta es afirmativa, se podría afirmar que, si fuera posible, las diligencias para mejor proveer podrían eventualmente desaparecer como ha ido desapareciendo todo lo relacionado con lo inquisitivo; si, en cambio, la respuesta fuera negativa, entonces simplemente se podría pensar que no tienen justificación.

Por ello considero que, más que buscar eufemismos, conviene llamar las cosas por su nombre: las diligencias para mejor proveer son de cuño inquisitivo y nada de mano hay en ello, si se piensa que la actuación positiva de los jueces puede constituir una muestra de un Estado proactivo que procura con sus acciones una mejor - más completa - solución a los problemas sociales. La práctica inquisitiva - si con ello entendemos oficiosa y necesaria - de las diligencias para mejor proveer dejan en mejor estado de salud a las partes y al Derecho mismo porque pueden permitir que los 
casos se resuelvan más cerca de ese ideal regulativo llamado justicia.

\section{Problemas epistemológicos}

Como se ha dicho anteriormente, la "búsqueda de la verdad" constituye la razón de ser de las diligencias para mejor proveer. La sola mención de este enunciado provoca de inmediato en la mayoría de los juristas prácticos (y en algunos teóricos) una curiosa sensación de "hartazgo previo", ya que, por extraño que parezca, quienes adoptan esa actitud muestran un cansancio por algo que todavía no han emprendido. Esa sensación suele presentarse ante la mayoría de los conceptos filosóficos o teóricos y que surge muy posiblemente del hecho de que entrar a su análisis a nada útil llevará y sólo se perderá el tiempo. Eso provoca que muchos juristas prácticos prefieran evitar encarar realmente esos conceptos y optar por no abordarlos o al menos no seriamente. Tal actitud - antifilosófica por antonomasia - no muestra más que un sencillo subterfugio que, adecuadamente abonado con la buena fama de "lo práctico", coloca a estas personas en una cómoda situación de desenfado y en una especie de triunfo frente a quienes suelen abordar tales conceptos. El triunfo, sin embargo, es pírrico, ya que lo que realmente constituye el reto es el problema y no las actitudes de unos y otros sujetos. Quien elude así el problema logra con seguridad mantenerse asido al estado de inopia.

Tratando de no caer en estos vicios, comentaré a continuación algunos problemas que pueden suscitarse a la hora de utilizar las diligencias para mejor proveer para lo que están hechas: mejor proveer al juez de elementos en la búsqueda de la verdad.

1. Un primer problema tiene que ver con la función que cumplen las diligencias para mejor proveer. Como hemos visto, éstas entran en acción cuando el juez no puede decidir entre dos o más posibilidades o versiones de los hechos que va a juzgar. Esto quiere decir que las diligencias para mejor proveer son instrumentos de carácter subsidiario y por ello se ubican al final de un procedimiento probatorio. Por ello, en cuanto a su función, no se las puede comparar con otro tipo de pruebas. Ahora bien: ¿en qué sentido podemos considerar que las diligencias para mejor proveer son pruebas?

El término "prueba", como se sabe, es sumamente ambiguo. Podemos servirnos de la estipulación que hace Marina Gascón (2004, pp. 83 y ss.) para distinguir entre tres sentidos del término "prueba", de los cuales el tercero será el sentido propio. Veamos: Primero, prueba como medios de prue$b a$ : todo aquello que permite conocer los hechos relevantes de la causa; lo 
que permite formular o verificar enunciados asertivos que sirven para reconstruir esos hechos. Ligada a esta primera distinción, la autora nos advierte que no confundir entre medio de prueba y fuente de la prueba. El medin de nrueha es el resultado de un nroceso de verificación awe se reali-

\begin{tabular}{|l|l|l|}
\hline & Fuente & Medio \\
\hline & $\begin{array}{l}\text { Persona y su conocimiento de los } \\
\text { hechos }\end{array}$ & La declaración \\
\hline Documental & Documento & El contenido \\
\hline Testimonial & Testigo & Testimonio \\
\hline $\begin{array}{l}\text { Pericial } \\
\text { judicial }\end{array}$ & Cosa, mate ria o persona & La actividad yel info me pericial \\
\hline $\begin{array}{l}\text { Diligencias para } \\
\text { mejor proveer }\end{array}$ & Lugar, cosa o persona & La actividad del reco nocimiento \\
\hline
\end{tabular}

Segundo, prueba como actividad probatoria: el procedimiento intelectivo (una constatación o una inferencia) mediante el cual, a partir de los medios de prueba, se conocen hechos relevantes para la decisión; es decir, se formulan o verifican enunciados asertivos sobre estos hechos. Tercero, prueba como resultado probatorio (o prueba en sentido estricto): lo que se obtiene a partir de los medios de prueba, a saber, el conocimiento ya obtenido del hecho controvertido o el enunciado fáctico verificado que lo describe. Los primeros dos sentidos del término prueba - señala Gascón - ("medios de prueba" y "actividad probatoria") cumplen una función cognoscitiva, porque permiten al juez conocer o "descubrir" los hechos, o sea, formular la prueba (en sentido de resultado probatorio), a partir de los elementos probatorios o de conocimiento introducidos por los medios de prueba. En cambio, la prueba como "resultado probatorio" o "prueba en sentido estricto" cumple una función justificatoria, porque constituye un elemento que sirve al juez para elegir racionalmente entre las diversas aserciones formuladas

\begin{tabular}{|c|c|c|}
\hline $\begin{array}{l}\text { Sentido de } \\
\text { "prueba" }\end{array}$ & Función & Ejemplos \\
\hline $\begin{array}{l}\text { Medios de } \\
\text { prueb a } \\
\text { Procedimiento } \\
\text { pro batorio }\end{array}$ & $\begin{array}{l}\text { Cognos citiv a } \\
\text { Cognos citiv a }\end{array}$ & 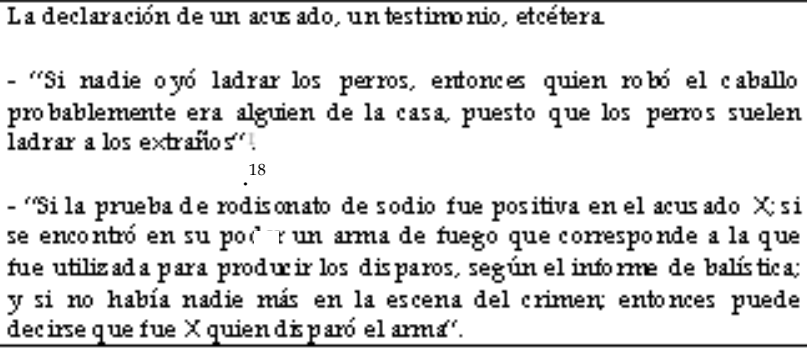 \\
\hline $\begin{array}{l}\text { Resultado } \\
\text { probatorio } \\
\text { (prueba en } \\
\text { sentido estric to) }\end{array}$ & Justific atoria & 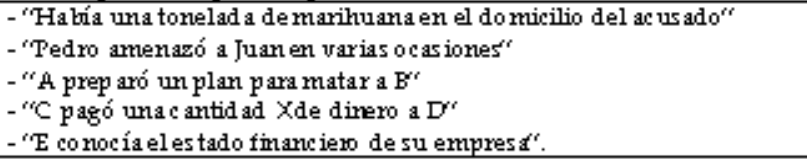 \\
\hline
\end{tabular}

${ }^{18}$ Ejemplo tomado de la famosa historia de Silver Blaze, de Sherlock Holmes, citado por Atienza, 2006, p. 82. 
en el proceso, confirmándolas o refutándolas. El siguiente cuadro da cuenta de estas distinciones:

Dicho lo anterior, parece más claro que las diligencias para mejor proveer, en un caso concreto, pueden ser analizadas como cualquier otro medio de prueba mediante inferencias de diverso tipo, y esperado un resultado probatorio que sea útil. Decía antes que no pueden cumplir la misma función que otras pruebas en el sentido de medios de prueba. Y creo que esto es así porque no son llevadas al proceso como cualquier otro medio de prueba, sino que son buscadas por el juez en una etapa de la motivación de los hechos en la que existen verdaderas dudas que le dificultan tomar una decisión acerca de cuál deba ser el resultado probatorio que se tenga por bueno. La diferencia, si se quiere, no es cualitativa, ya que una diligencia para mejor proveer puede ser otro testimonio, otro documento u otro lo que sea; se trata, más bien, de una diferencia que podríamos llamar definitoria en el sentido de que con la práctica de la diligencia el juez puede terminar de decidir cuáles son los hechos probados en un determinado caso problemático, es decir, que ofrece más de alguna posibilidad viable. En una palabra: la función que cumple este tipo de prácticas es justificatoria más que cognoscitiva ya que, auque cumple inicialmente una función de segundo tipo, lo determinante y fundamental de su utilización o manejo a cargo del juez es su carácter definitorio. No puedo dejar de pensar en el legendario Sherlock Holmes cuando en sus aventuras regularmente termina complementando la comprobación de su hipótesis con un último dato o cabo suelto que a la mitad del problema no estaba en sus manos. Sus "clientes" o quienes precisaban de sus servicios regularmente le daban una serie de datos incompletos y él, de manera oficiosa, acudía a recoger in situ el resto de datos que le hacían falta.

2. Veamos ahora las diligencias para mejor proveer en su carácter de procedimiento probatorio. Volviendo con Marina Gascón, éstos pueden ser de diversos tipos (Id., pp. 86 y ss.)::

A) Las pruebas directas: procedimiento de conocimiento de hechos (o de verificación de enunciados fácticos) basado en la observación del propio sujeto juzgador. La relevancia epistemológica es de certeza absoluta; por ejemplo, el conocimiento de datos a través de documentos públicos o privados; la información que el juez obtiene mediante el desahogo de un careo constitucional; el análisis de las declaraciones, etcétera.

B) Las pruebas deductivas: procedimiento de conocimiento de hechos (o de verificación de enunciados fácticos) basado e una inferencia deductiva a partir de otras aserciones verificadas. También en estas pruebas existe una relevancia epistemológica absoluta, ya que se trata de una operación 
de lógica formal en la que el conocimiento que arroja la conclusión del razonamiento depende absolutamente de la premisa mayor dada, precisamente, por un enunciado verdadero derivado de una prueba directa. Por ejemplo, dada una prueba científica (directa) de paternidad por ADN mediante la que se demuestra que Juan es hijo de Pedro, es posible deducir que Juan es hermano de María, por lo que, en principio, ambos podrían heredar a Pedro.

C) Prueba indirecta o inductiva: procedimiento de conocimiento de hechos (o de verificación de enunciados) basado en inferencias de carácter inductivo a partir de otras aserciones verificadas. Por ejemplo, las sorprendentes "deducciones" de Sherlock Holmes que, una vez explicadas por él - a partir de agudas observaciones de detalles mínimos, vasta experiencia y una increíble capacidad de encontrar la coherencia narrativa - parecían cosa de niños. El siguiente pasaje resulta ilustrativo de este tipo de inferencias:

-Entonces, Watson - dijo [Sherlock Holmes] de repente- , ¿no piensa invertir ningún dinero en títulos sudafricanos?

Me sobresalté, asombrado. Acostumbrado como estaba a las curiosas facultades de Holmes, esa repentina intrusión en mis pensamientos más íntimos me parecía absolutamente inexplicable.

- ¿Cómo demonios lo sabe? - pregunté.

El se dio la vuelta en el taburete, con un humeante tubo de ensayo en la mano y un fulgor de diversión en sus hundidos ojos.

- Vamos, Watson, confiese que se ha quedado completamente abrumado - dijo.

- Es verdad.

- Debería hacerle firmar un papel que lo declarara.

- ¿Por qué?

- Porque dentro de cinco minutos dirá que todo esto es ridículamente sencillo.

- Estoy seguro de que no diré nada parecido.

- Vea, mi querido Watson [...] no es muy difícil establecer una serie de inferencias, cada una de ellas derivadas de su precedente y todas ellas muy sencillas. Si después de hacerlo así, uno simplemente rebate todas las inferencias intermedias y presenta a su público el punto de partida y la conclusión, puede producir un efecto sorprendente, aunque posiblemente engañoso. Bueno, no era realmente difícil, observando el surco entre su índice izquierdo y el pulgar, tener la certeza de que usted no se proponía invertir su pequeño capital en las minas de oro. - No veo la relación.

-Es muy probable que no; pero puedo mostrarle rápidamente una 
estrecha conexión. Aquí están los eslabones de esta sencillísima cadena: 1: Usted tenía tiza anoche entre el índice izquierdo y el pulgar al volver de su club. 2: Usted se pone tiza ahí cuando juega al billar para que no le resbale el taco. 3: Usted no juega nunca al billar si no es con Thurston. 4: Usted me dijo hace cuatro semanas que Thurston tenía una opción en unas propiedades sudafricanas que expiraban dentro de un mes, y que quería compartir con usted. 5: Su libreta de cheques está guardada en mi cajón, y no me ha pedido la llave. 6: No se propone invertir su dinero de esa manera.

- ¡Es ridículamente sencillo! - exclamé.

- ¡Eso es! - dijo, un poco irritado - . Todos los problemas parecen infantiles una vez que se explican (Connan Doyle, 1903, p. 50).

Pues bien, las diligencias para mejor proveer pueden ser puestas en práctica a través de cualquiera de estos procedimientos probatorios, es decir, pueden dar lugar a comprobaciones directas, deductivas o inductivas. Sin embargo, por sus propias características, estas diligencias parecen "pedir" ser usadas de manera más frecuente como procedimientos indirectos o inductivos, ya que si los datos que necesita el juez pudiesen ser localizados mediante procedimientos de prueba directa o deductiva, habría sido muy probable que las partes (incluso en asuntos penales) las hubieran llevado al juicio, ya de manera directa o ya excitando al propio juez a que las buscase. Se trata, sin embargo, de una cuestión de probabilidad.

En este sentido, considero que los jueces debieran estar mejor preparados en cuestiones tales como las inferencias inductivas o abductivas; ${ }^{19}$ considerar que, bien practicadas, este tipo de inferencias son racionales y perfectamente utilizables por los tribunales. Para quienes dudan de la seriedad de estos procedimientos, conviene advertir que el desarrollo teórico en la actualidad es amplio y ha tenido gran incidencia práctica. En efecto, en los últimos años algunos autore ${ }^{20}$ han tomado como tarea examinar los problemas relacionados con el aspecto fáctico de la argumentación o la llamada "motivación de los hechos". Se trata, como se sabe, de una aproximación algo distinta de lo que se conoce como "Derecho probatorio" o "teoría de la prueba" que tradicionalmente han abordado los procesalistas. Lo que distingue a los primeros de los segundos es la elaboración de los llamados estándares de racionalidad epistemológica, que no son otra cosa que herramientas intelectuales que permiten al operador determinar de manera ra-

\footnotetext{
${ }^{19}$ Un excelente artículo sobre el particular es el escrito por Pablo Raúl Bonorino "Sobre la abducción", en Doxa. Cuadernos de Filosofía del Derecho, número 14, Departamento de Filosofía del Derecho de la Universidad de Alicante, 1993.

${ }^{20}$ Por ejemplo, Larry Laudan, Luigi Ferrajoli, Michelle Taruffo, Perfecto Andrés Ibáñez, Marina Gascón Abellán, Manuel Miranda Estampres, Daniel González Lagier, Jordi Ferrer Beltrán, entre otros.
} 
zonable y medible en qué medida o grado un hecho se tiene por probado. Estos autores han demostrado lo útil que resulta para un operador jurídico el empleo de herramientas intelectuales propias del campo de la epistemología que tradicionalmente no han sido tomadas en cuenta por los juristas. Así, por ejemplo, para acreditar la fuerza probatoria de una inferencia basada en pruebas indirectas existe el siguiente procedimiento: ${ }^{21}$

Primer paso: aplicar a los medios de prueba el siguiente test:

a) Que los indicios estén plenamente acreditados (fiabilidad)

b) Que concurra una pluralidad y variedad de indicios (cantidad)

c) Que tengan relación con el hecho ilícito y su agente (pertinencia)

d) Que tengan armonía o concordancia (coherencia)

e) Que el enlace entre los indicios y los hechos constitutivos del ilícito se ajuste a las reglas de la lógica y a las máximas de experiencia ( $g a$ rantía bien fundada)

f) Que se eliminen hipótesis alternativas

g) Que no existan contraindicios (no refutación)

Segundo paso: tomar en cuenta una garantía, es decir, un parámetro que permita determinar si los hechos sometidos a análisis tienen algún valor probatorio. Por ejemplo, podrían utilizarse algunas reglas de valoración de la prueba de algún código de procedimientos como el Federal de Procedimientos Penales, para los casos en materia penal.

Tercer paso: construir una hipótesis en cualquiera de estos dos sentidos: los hechos son de tal naturaleza que merecen ser investigados o los hechos son de tal naturaleza que no ameritan mayor indagación. La hipótesis que se proponga debe pasar por el siguiente test:
a) ¿Ha sido refutada?
b) ¿Se han podido confirmar las hipótesis derivadas?
c) ¿Se han eliminado hipótesis alternativas?
d) ¿Es coherente?
e) ¿Es simple?

3. Corresponde ahora analizar cómo son las diligencias para mejor proveer de acuerdo con la categoría de "resultado probatorio" o "pruebas en sentido estricto". Las pruebas así vistas todavía pueden ser clasificadas a

\footnotetext{
${ }^{21}$ Miranda Estampres, M., La mínima actividad probatoria en el proceso penal, J.M. Bosch Editor, Barcelona, 1997, pp. 231 y ss.
} 
través de tres criterios (Gascón, pp. 94 y ss.):

\subsection{Por El TIPO DE PROCEDIMIENTO PROBATORIO}

- Constataciones o enunciados de observación: resultado de una prueba directa

- Conclusiones: las que se obtienen mediante prueba deductiva

- Hipótesis: las que se obtienen mediante prueba indirecta

\subsection{Por el uso Que Se de a la prueba}

- Prueba a secas: enunciado fáctico resultante de un procedimiento probatorio

- Enunciado probatorio: enunciado fáctico verificado que es usado como premisa

\subsection{Por el VAlor probatorio}

- Prueba plena: la que tiene el valor suficiente para fundas por sí sola una decisión judicial sobre un hecho que se pretende probar

- Prueba no plena: la que no es idónea ni suficiente para fundar por sí sola la decisión; opera conjuntamente con otros enunciados probatorios mediante un procedimiento de prueba indirecta o inductiva; se las considera como indicios.

Los resultados probatorios que producen las diligencias para mejor proveer pueden manifestarse a través de cualquiera de las categorías anteriores; sin embargo, parecen estar más llamadas a producir hipótesis, premisas de una inferencia probatoria y pruebas no plenas. Recordemos que las diligencias se usan para complementar la convicción del juez; ello implica que, cuando decide ordenar una diligencia para mejor proveer, el juzgador cuenta ya con ciertos medios de prueba y posiblemente hubo realizado diferentes procedimientos probatorios. Muy probablemente, el juez no tenga todavía resultados concluyentes, es decir, pruebas en sentido estricto y eso mismo lo motivó a ordenar la diligencia.

4. Por otro lado, cabe preguntarse: ¿a qué responden estas diligencias: 
a la insuficiencia de la convicción o a la detección de una defectuosa actividad probatoria? Si uno se inclina por la segunda opción, entonces podría decirse que el acento se coloca en el carácter inquisitivo de la actividad judicial, porque supone una preocupación por la conducta procesal de las partes que ha de ser corregida por la autoridad. Si, por el contrario, se considera que se trata sólo de un problema epistemológico, entonces desaparece la dicotomía inquisitivo-dispositiva, para más bien situarse en un plano técnico en el que el juzgador ha de resolver el conflicto con la máxima convicción posible sobre los hechos examinados.

La actitud de un juez comprometido realmente con la verdad le llevará a utilizar todos los recursos legales a su alcance para dar por probados los hechos, sin menoscabo de las reglas que regulan el equilibrio procesal. Por ello, no son aceptables las posiciones según las cuales el juez debe limitarse a lo actuado por las partes y resolver, digamos, de espaldas a la realidad. No hay, pues, una "verdad legal" como algo distinto de una "verdad verdadera". El proceso no puede verse como un escenario en el que se monta una realidad alternativa o acordada por las partes; debe verse como un medio artificial, sí, en el que las instituciones del Estado garantizan una solución de los conflictos bajo el imperio de la ley. Y este imperio tan renombrado abarca desde luego la actividad probatoria y, puede decirse, pretende algo más: una suerte de imperio de la verdad visto como ideal regulativo. Los juzgadores no son meros árbitros que median entre las partes, los juzgadores, especialmente en Derecho público, son auténticos protagonistas en el juego de la verdad; la persiguen, la buscan y se comprometen con ella para producir libertad, como diría la máxima.

5. Para terminar, nos preguntamos: ¿cuáles son los límites de la oficiosidad de las referidas diligencias? Las anteriores reflexiones nos llevan, desde luego, a buscar algún limite, pues una actuación absolutista del juez que diera la espalda a las partes sería tan reprobable como una actitud timorata con respecto a las mismas partes. La actuación del juez es una manifestación de poder y como tal debe estar controlado. El imperio de la ley vuelve a hacerse presente. Los jueces también deben ceñir su actuación a las reglas y principios del sistema, especialmente con respecto a los derechos fundamentales que se ponen en juego a la hora de ejercer la jurisdicción. El proceso judicial está específicamente regulado; cada procedimiento marca las etapas, los términos, plazos y conductas concretas que el juez debe respetar y saber administrar. En eso no hay duda posible. Sí la hay, en cambio, en el ejercicio de la discrecionalidad o arbitrio judicial. Las diligencias para mejor proveer son un buen ejemplo de ejercicio discrecional.

Entonces: ¿qué regula la discrecionalidad? ¿qué determina que el juez 
pueda decidir legalmente si lleva a cabo o no una diligencia de este tipo? Alejandro Nieto (2000, p. 203) sostiene que el sistema de arbitrio judicial y el sistema de legalidad forman una unidad imprescindible: "tan falso e incompleto es un principio de arbitrio que prescinde de la legalidad como un principio de legalidad que prescinde del arbitrio". La razón de lo anterior es que la legalidad necesita del arbitrio para ser efectiva tanto como el arbitrio necesita de la legalidad para ser lícito. Pues bien, a mi juicio, el ejercicio discrecional de las diligencias para mejor proveer no puede verse como desvinculado a un deber. El hecho de que el ejercicio sea discrecional no implica que sencillamente se decida como quien echa una moneda al aire si la diligencia se practica o no se practica. Eso sería un uso arbitrario de la facultad discrecional. El juzgador no puede darse el lujo de decidir estomacalmente si practica o no la diligencia. Por el contrario, si está consciente de la necesidad de allegarse más medios de prueba para complementar un proceso probatorio y obtener así pruebas en sentido estricto para tomar la decisión, entonces debe ejercer su facultad. Desde mi punto de vista, el uso discrecional de cualquier facultad debe ser visto como un deber: el deber consiste precisamente en el uso (adecuado al caso concreto) de la facultad discrecional, y su incumplimiento derivaría de un no ejercicio de la facultad en aquellos casos en que se hacía necesario.

Este deber "vive", por cierto, muy cerca de la casa de las virtudes del juez; concretamente es vecino de la prudencia y la templanza. La primera, en el caso de los jueces, debe ser entendida como "frónesis", esto es, la virtud de la inteligencia práctica, de la capacidad necesaria para aplicar adecuadamente los principios generales a las situaciones particulares. Anthony Kronman (Cfr. Atienza, 2001-1, p. 141) señala que la virtud, en términos de inteligencia o sabiduría práctica, es algo así como una síntesis de varios factores: habilidad dialéctica, capacidad discursiva o argumentativa, intuición, deliberación y reflexión. Dice Kronman que el juicio prudente es, necesariamente, un juicio reflexivo, una especie de síntesis entre el pensamiento abstracto y la experiencia del mundo. Ahora que para llevar a cabo dicha síntesis se requiere la facultad de la imaginación en la que, a su vez, pueden distinguirse dos aspectos: por un lado, el estético, que se refiere a la imaginación como capacidad de invención, de ir más allá de la realidad, de sugerir una pluralidad de alternativas para resolver un problema; por otro lado, está el aspecto moral que consta, a su vez, de otros dos elementos: la simpatía o compasión, esto es, el ser capaz de ponerse en el lugar del otro; y la capacidad para mantener cierta distancia en relación con los otros y con las cosas, para adoptar una actitud de cautela y de serenidad. En palabras de Kronman, las cualidades que constituirían el carácter profesional del juez serían “...conocimiento del mundo, cautela, escepticismo frente a ideas y programas establecidos en un nivel muy alto de abstracción y espí- 
ritu de simpatía distante que se desprende de un amplio conocimiento de las flaquezas de los seres humanos" (Kronman, 1986, 232)..

La templanza, según Aristóteles, es "...[la] virtud por la cual se está dispuesto para los placeres del cuerpo en la medida en que la ley manda; desenfreno es lo contrario" (Aristóteles, Retórica, Libro I, § 9). Manuel Atienza señala que la templanza, trasladada al ámbito judicial, podría llamarse autorrestricción, la cual consiste "[en] la cualidad que debe disponer al juez a usar moderadamente el - extraordinario - poder de que está investido, a considerar que los límites de ejercicio de ese poder no son únicamente los establecidos por las normas, a esforzarse por no imponer a los otros sus propias opiniones, ideologías, etc." (Atienza, 2001-1, 140 y 141).

\section{A MANERA DE CONCLUSIÓN: DOS ENFOQUES, UNA REALIDAD}

Las diligencias para mejor proveer representan la oportunidad institucional para que los jueces maximicen su convicción a la hora de resolver problemas relacionados con la prueba o la calificación normativa de los hechos. Su carácter inquisitivo, desde el punto de vista procesal, nada tiene que ver con el desequilibrio o la ruptura de principios ordenadores del proceso, pues, bien utilizadas, estas medidas están dispuestas al servicio de la verdad como mejor garantía de acercarse a la idea de resolver conflictos conforme a la justicia más que conforme a Derecho.

En la difícil tarea de construir inferencias probatorias, los juristas suelen colocarse en cualquiera de estos dos extremos: 1) resolver a partir de lo estrictamente actuado por las partes, aun cuando existan dudas razonables acerca de lo que realmente ocurrió (problemas de prueba); o 2) desarrollar estrategias de razonamiento probatorio a partir de inducciones o procesos de abducción en los que cobra gran valor la coherencia narrativa y queda un poco más expuesto el hecho de que los resultados probatorios (pruebas en sentido estricto) no son absolutamente verdaderos pero sí altamente probables. A mi juicio, las inferencias probatorias mencionadas en segundo lugar pueden ser más aceptables cuando para llegar a ellas se despliega la actuación del Estado a través de las diligencias para mejor proveer. Ello, porque la actuación queda formalizada y porque el ejercicio de estas medidas implica, por un lado, que el juzgador debió justificar la duda razonable $\mathrm{y}$, por otro, porque la búsqueda de datos adicionales a los traídos por las partes al proceso mejora sin lugar a dudas la práctica de las inferencias probatorias, especialmente cuando se utilizan pruebas indirectas.

No quiero dejar de mencionar una serie de casos que ha resuelto la Suprema Corte de Justicia de la Nación en los que se ha echado mano de las 
diligencias para mejor proveer. Por cierto, conviene señalar que estos casos tuvieron gran impacto social, en parte porque fueron presentados como auténticos amicus curiae y no como diligencias para mejor proveer. Quiero pensar que la lectura positiva que la prensa y la academia hicieron de estos casos estuvo influida por el prestigio del que goza la institución anglosajona $\mathrm{y}$, como suele suceder con casi todo aquello que proviene de esa tradición, se pensó que, por haber utilizado por primera vez esas medidas, la Suprema Corte había entrado, por fin, a la modernidad.

En tales asuntos se platearon cuestiones de carácter científico o tecnológico que estaban fuera de la órbita de conocimiento de los ministros, por lo que quedó perfectamente justificado el uso de estas diligencias. El primero, fue el Amparo en Revisión 2146/2005, fallado por el Tribunal Pleno el 27 de febrero de 2007. En él, se declararon inconstitucionales las normas contenidas en la fracción IV del artículo 24 y la fracción 45 (segunda categoría) del artículo 226 de la Ley del Instituto de la Seguridad Social de las Fuerzas Armadas. ${ }^{22}$ Para nuestro país, este asunto supuso un parteaguas, porque no fue fácil la aceptación de que se acudiera a una autoridad científica - en el caso, la Academia Mexicana de Ciencias - tal como se refleja en el siguiente pasaje del voto concurrente del Ministro José Ramón Cossío:

La discusión en torno a la legitimidad de recurrir a dictámenes de especialistas para determinar si una ley resulta o no inconstitucional ha sido una de las más intensas, y sustenta en buena parte la división entre la mayoría y la minoría en el presente asunto. A mi juicio, gran parte de esta discusión ha sido propiciada por la confusión entre, por un lado, lo que son herramientas cuyo uso resulta legítimo para integrar la premisa fáctica del razonamiento - una discusión que gira en torno a los medios de prueba y las cargas que las partes deben soportar en esa materia - y por otro, lo que son elementos que el juez necesita para atribuir significados a las normas y determinar si una norma respeta a otra. Si contemplamos la realidad desde la distinción primordial entre "hechos" y "derecho", lo que hemos estado dilucidando durante la discusión del caso cae en todo momento en el ámbito del "derecho" - y la determinación del derecho aplicable al caso, así como su interpretación, no es responsabilidad de las partes, sino del juez-.

De ahí la falta de pertinencia del señalamiento, elevado por algunos

\footnotetext{
${ }^{22}$ Conforme a la primera disposición, una de la hipótesis en las que procede retirar a un militar del activo del Ejército (colocándolo, según la terminología de la ley, "en situación de retiro") es "[q]uedar inutilizado en actos fuera del servicio". El artículo 226, por su parte, establece que "para la determinación de las categorías y grados de accidentes o enfermedades que den origen a retiro por inutilidad se aplicarán las siguientes tablas: (...) Segunda Categoría (...) 45. La seropositividad a los anticuerpos contra los virus de la inmunodeficiencia humana confirmada con pruebas suplementarias".
} 
ministros, según el cual en nuestro sistema jurídico los juzgadores de amparo no pueden legalmente allegarse de elementos que no hayan sido planteados por las partes $\mathrm{u}$ ofrecidos como pruebas por ellas para ilustrar su criterio. Desde su perspectiva, más allá del deber de considerar los documentos integrados en el expediente, resulta improcedente interesarse por lo que los especialistas médicos tienen que decir sobre el VIH, el SIDA y su efecto en la capacidad o incapacidad ("utilidad" o "inutilidad") para desarrollar la actividad propia de los miembros de las Fuerzas Armadas mexicanas.

La Suprema Corte de Justicia de la Nación, finalmente, envió un cuestionario a la Academia Mexicana de Ciencias que fue respondido puntualmente y sirvió para despejar más de una duda de los ministros y consolidó su convicción con respecto de temas tan delicados como complejos desde el punto de vista científico que desembocaban en el problema central: el posible estado de "inutilización" de los miembros de las Fuerzas Armadas que en las pruebas analíticas correspondientes hubieren sido confirmadas como portadoras del VIH. Se plantearon preguntas tales como ¿cuál es, más específicamente, el impacto de la condición de ser seropositivo tratado en la capacidad de desempeñar un trabajo? $\mathrm{O}$ ¿existen criterios médicos que identifiquen ciertos trabajos o actividades como "de riesgo" desde la perspectiva de la posibilidad de transmitir el VIH a otras personas?

El fundamento de la práctica de esta entrevista y de la presencia de los científicos en la Sala de Audiencias del Tribunal Pleno de la Suprema Corte de Justicia de la Nación no pudo ser otro que el de las diligencias para mejor proveer, según se puede ver en el cuerpo de la propia sentencia, aunque, hay que decirlo, de manera no muy enfática:

[ ]. Sin embargo, la diferenciación legal es inadecuada para alcanzar dicha finalidad constitucional legítima, porque la ciencia médica, reflejada en distintas normas nacionales y directrices internacionales, han demostrado la inexactitud de la decisión - cuando se pretende que en automático y desde la ley de que los militares son inútiles y están incapacitados per se para formar parte del Ejército, por el simple hecho de tener seropositividad a los anticuerpos contra el virus de la inmunodeficiencia humana - VIH - confirmada con pruebas suplementarias.

Asimismo, la ciencia médica, reflejada también en distintas normas nacionales e internacionales, ha dejado claro que no supone ningún beneficio para la salud pública aislar a una persona que tiene el VIH o SIDA simplemente por razón de la infección respectiva, puesto que ese 
padecimiento no puede transmitirse mediante el contacto casual o por vía respiratoria.

Esta interpretación jurídica está respaldada no sólo por la información médica allegada por miembros del Máximo Tribunal del país con base en el artículo 79 del Código Federal de Procedimientos Civiles, de aplicación supletoria a la Ley de Amparo, sino también por las siguientes directrices nacionales e internacionales de carácter especializado [... $].{ }^{23}$

El artículo 79 del Código Federal de Procedimientos Civiles es, como se ha dicho a lo largo de este trabajo, el fundamento de las diligencias para mejor proveer a nivel federal, incluyendo, desde luego, al juicio de amparo.

Meses más tarde, durante el mismo 2007, la Suprema Corte de Justicia de la Nación resolvió otro polémico asunto en el que volvió a solicitar este tipo de diligencias para mejor proveer: la Acción de Inconstitucionalidad 26/2006, promovida por los senadores integrantes de la Quincuagésima Novena Legislatura del Congreso de la Unión, que versó sobre la constitucionalidad de la llamada "Ley Televisa". La sentencia, emitida el 7 de junio, tuvo como uno de sus ejes estructurales la opinión de varios expertos del Instituto Politécnico Nacional y de la Universidad Nacional Autónoma de México, como se puede apreciar en el siguiente fragmento:

Es decir, los actuales concesionarios de televisión abierta pueden instalar una red distinta de la radiodifusión para prestar otros servicios de telecomunicaciones como celular y servicios de banda ancha con una autorización, es decir, la maximización de sus ganancias, a costa de la posibilidad de la existencia de otros medios de comunicación, como quedó demostrado en la respuesta que dieron los expertos en la Sesión de 22 de mayo, a la primera pregunta que les realicé.

Pregunté, ¿podría un concesionario de radiodifusión que transmita señal digital en calidad inferior a HDTV, -o sea, Televisión Digital de Alta Definición-, destinar el espectro liberado para prestar servicios de telefonía fija o móvil, utilizando para ello la tecnología adecuada, así como redes adicionales que permitieran realizar una transmisión bidireccional?

A lo anterior, con toda claridad el ingeniero Rodolfo de la

${ }^{23}$ Sentencia AR 2146/2005, p. 106, resuelta por el Tribunal Pleno de la Suprema Corte de Justicia de la Nación, de fecha 27 de febrero de 2007. 
Rosa Rábago, experto del IPN, contestó: “La respuesta tal y como está planteada utilizando para ello la tecnología adecuada así como redes adicionales; la respuesta es: Sí, sin ningún problema; o sea, no necesariamente voy a utilizar el espectro liberado o no porque usemos HDTV, o MDTV, o la otra la estándar, MDT, no importa, si vamos a utilizar otra tecnología, sí podemos prestar otros servicios. La respuesta tal como está planteada es: Sí."

Asimismo, el actuario José Fabián Romo Zamudio, experto de la UNAM indicó: "Coincido con el ingeniero, la respuesta directa a la pregunta con toda esa tecnología es: Sí, ..." 24

Otro asunto en el que la Suprema Corte utilizó las diligencias para mejor proveer fue la Acción de Inconstitucionalidad 146/2007 y su acumulada 147/2007, promovida por la Comisión Nacional de los Derechos Humanos y la Procuraduría General de la República, la cual fue resuelta el 28 de agosto de 2008. En este asunto se analizó la constitucionalidad de los artículos 144, 145, 146, 147 y 148 del Código Penal para el Distrito Federal, así como la adición de los artículos 16 Bis 6, tercer párrafo, 16 bis 7 y 16 Bis 8, último párrafo, de la Ley de Salud para el Distrito Federal. Estas normas básicamente regulan la despenalización del aborto durante las primeras 12 semanas de gestación.

En este caso, la Suprema Corte de Justicia de la Nación solicitó informes, pruebas y estudios de carácter ético, moral, filosófico, científico y legal sobre el momento a partir del cual empieza la vida humana y el momento a partir del cual debe protegerse por el Estado; de hecho, por primera vez en la historia, ordenó la celebración de diversas sesiones de comparecencia, a fin de que las asociaciones o agrupaciones, al igual que los particulares que desearan exponer sus puntos de vista en relación con el tema, manifestaran sus ideas en audiencia pública presidida por el Ministro Presidente y por los ministros que se encontraran presentes. Para ello, se emitió un acuerdo el 31 de marzo de 2008, con apoyo en el Acuerdo Plenario 2/ 2008, de 10 de marzo del mismo año, en cuyo fundamento se encuentra citado el artículo 79 del Código Federal de Procedimientos Civiles, sede legal, como se ha dicho, de las diligencias para mejor proveer.

$* * *$

Los casos anteriormente relatados muestran que en México empieza a experimentarse un giro en la cultura judicial, especialmente a nivel de la 
interpretación constitucional. De acuerdo con estos cambios, cada vez va quedando más claro que el juez cobra (o debe cobrar) más protagonismo en el proceso, aun incluso en Derecho privado. La búsqueda de la verdad por el juez es un asunto de interés superior que debe constituir un ideal regulativo. El juzgador pasivo, poco audaz y conformista no se corresponde con las expectativas sociales de estos tiempos. Necesitamos jueces que no sólo conozcan el sistema procesal sino que lo sepan utilizar adecuadamente, maximizando todas las posibilidades legales en aras de un mejor conocimiento de la cuestión que va a resolverse; en suma, necesitamos jueces que se comprometan con un genuino conocimiento de los hechos.

Este tipo de jueces han de entender que es tan importante el manejo adecuado de las instituciones procesales como el conocimiento de las estrategias de razonamiento en materia de hechos. No se trata de que triunfe la técnica procesal sobre la epistemología judicial ni viceversa; lo que se busca es un complemento entre ambas cuestiones en función de un equilibrio pragmático entre las posibilidades teóricas y prácticas; entre el correcto manejo del proceso y de la teoría. No es posible aceptar actitudes antifilosóficas que se niegan a teorizar cuando se hace necesario, ni tampoco audacias irreflexivas que intentan resolver problemas desde el Derecho sin atender las reglas (procesales) del juego. Después de todo, todos, teóricos y prácticos buscamos mejorar nuestro quehacer en función de una mejor solución de los conflictos.

\section{BIBLIOGRAFÍA}

Aristóteles (2002): Arte poética; arte retórica, México, Porrúa.

Atienza, Manuel (1993): Tras la Justicia. Una introducción al Derecho y al razonamiento jurídico, Barcelona, Ariel.

Atienza, Manuel (1997): Las razones de Derecho, Madrid, Centro de Estudios Constitucionales.

Atienza, Manuel (2001-1): “Virtudes judiciales, Sobre la selección y formación de los jueces en el Estado de Derecho", en Cuestiones Judiciales, México, Fontamara.

Atienza, Manuel (2001-2): “¿Qué puede hacer la teoría por la práctica judi-

${ }^{24}$ Sentencia AI-26/2006, de fecha 7 de junio de 2007, páginas 72 y 73. 
cial", en Cuestiones Judiciales, México, Fontamara.

Bonorino, Pablo Raúl (1993): “Sobre la abducción”, en Doxa. Cuadernos de Filosofía del Derecho, número 14, Alicante, Departamento de Filosofía del Derecho de la Universidad de Alicante.

Calamandrei, Piero (1951): “Un maestro del liberalismo procesal”, en Revista Argentina de Derecho procesal, 1951, números 1-2.

Connan Doyle, Sir Arthur (1903): "Los hombrecitos danzantes" en El regreso de Sherlock Holmes; edición castellana El misterio del valle de Boscombe y otras aventuras de Sherlock Holmes, traducción de María Campuzano y José Ma. Varlverde, Barcelona, editorial Bruguera, 1981.

Davis Echandía, Hernando (1997): Teoría General del Proceso, Buenos Aires, Editorial Universidad.

Fix-Zamudio, Héctor (1964): El juicio de amparo, México, Porrúa.

Gascón Abellán, Marina (2004): Los hechos en el Derecho. Bases argumentales de la prueba, Madrid, Marcial Pons.

Guasp, Jaime (1943), Comentarios a la Ley de enjuiciamiento civil, Madrid, tomo I.

Kronman, Anthony T. (1986): "Practical Widsom and Profesional Character", en Social Philosophy and Policy, nr. 4, 1986.

Lara Chagoyán, Roberto (2004): El concepto de sanción en la teoría contemporánea del Derecho, México, Fontamara.

MacCormick, Neil (1978), Legal Reasoning and Legal Theory, Oxford University Press.

Martín Ostos, José de los Santos (1981): Las diligencias para mejor proveer en el proceso civil, Madrid, Editorial Montecorvo.

Nieto, Alejandro (2000): El arbitrio judicial, Barcelona, Ariel.

Ost, François (1993), "Júpiter, Hércules y Hermes: tres modelos de juez", Doxa. Cuadernos de Filosofía del Derecho, número 14, Alicante, Departamento de Filosofía del Derecho. 
Picó i Junoy (2007): Joan Picó i Junoy, El juez y la prueba. estudio de la errónea recepción del brocardo iurex iudicare debet secundum allegata et probata, non secundum conscientiam y su repercusión actual, Barcelona, 2007, J. M. Bosch Editor.

Tomás y Valiente, Francisco (1969): El derecho penal de la Monarquía absoluta, Madrid 1969. 